\title{
PRÁXIS LEGISLATIVA - PENSAR FAZENDO, FAZER PENSANDO
}

\author{
Sinara Porto Fajardo*
}

Resumo: Descrição da implementação de um projeto de grupos de estudos entre servidores da Assembléia Legislativa do Rio Grande do Sul. O objetivo deste artigo é descrever e oferecer subsídios para debate sobre um projeto implementado, entre 2005 e 2006, na Assembléia Legislativa do Rio Grande do Sul, por intermédio da Escola do Legislativo Deputado Romildo Bolzan. Trata-se da criação e implementação de grupos de estudos e reflexão compostos de servidores e servidoras, abordando principalmente a metodologia de pesquisa inicial para definição de temas, o perfil dos servidores e servidoras voluntários no projeto e uma breve avaliação do processo.

Palavras-Chave: serviço público; parlamento; grupos de estudos; formação continuada.

Resumen: Implementación de um proyecto de estudio en grupos con funcionarios de la Asemblea Legislativa de Rio Grande del Sur. Describe y discute el proyecto, que fue inplementado entre los años 2005 y 2006 en la Asenblea Legislativa, por intermédio de la Escuela del Legislativo Dep. Romildo Bolzan. Aborda la creación y la implementación de grupos de discusión y de estudio. Presenta la metodologia utilizada para la nucleación de los grupos, la definición de temas y discute el perfil de los participantes. Avalición del proceso.

Palabras Clave: servicio público; parlamento; grupos de discusión; formación.

\section{O Projeto Práxis Legislativa}

Doutora em Direitos Humanos e Libertades Fundamentais pela Universidad de Zaragoza, Espanha. Assistente Social, assessora da Presidência da Assembléia Legislativa do Rio Grande do Sul. sinara.fajardo@al.rs.gov.br 
Práxis - que indica um processo de "pensar fazendo/fazer pensando", foi um espaço de estudo e reflexão sobre o "serviço público", seus fundamentos, determinações e perspectivas no panorama atual da organização sociopolítica e sobre os desafios do Poder Legislativo no processo de consolidação democrática. Oportunizou convivência, intercâmbio de conhecimentos e de experiências entre os servidores, contribuindo para superar supostas estratificações entre colegas novos e antigos e entre a chamada área administrativa e área política, criando uma unidade plural no corpo funcional. Proporcionou momentos de construção de bases para projetos de pesquisa e de avaliação institucional, a partir das contribuições do próprio corpo funcional da Assembléia Legislativa.

O projeto Práxis Legislativa justificou-se, inicialmente, como uma forma de atender as necessidades do corpo funcional da Assembléia Legislativa, de reforçar aspectos motivadores (coleguismo e relacionamento; reconhecimento; aprendizado; desafio; diálogo), maximizar motivações (interatividade entre colegas novos e antigos; continuidade e intensificação de programas de integração entre servidores e departamentos), enfrentar aspectos desmotivadores (acomodação/desmotivação; falta de comunicação entre setores; relacionamento com colegas mais antigos) e implementar um plano de ação (fortalecimento e valorização do quadro funcional, atualização, comprometimento com projetos/planos a longo prazo). Propôs-se, também, a desencadear um processo de formação continuada, articulando teoria (contextualização e fundamentação das ações profissionais, políticas e técnicas do parlamento) e prática (reflexão, troca de experiências, crítica e autocrítica solidária, valorização de saberes construídos no cotidiano) com o conjunto de servidores da Assembléia Legislativa.

\section{O público destinatário}

Inicialmente, o projeto pretendeu acolher funcionários e funcionárias da Assembléia Legislativa, independentemente do vínculo com o Estado, visando contribuir para a constituição de um espírito de corpo que pudesse abranger a totalidade do quadro de pessoal. Com o decorrer dos debates, entretanto, foi ficando clara a diferença teórica e empírica entre servidores do quadro efetivo e de cargo de confiança. Assim, no decorrer do processo, o público destinatário passou a ser prioritariamente os servidores e servidoras do quadro efetivo da Casa, tanto da área administrativa como política ou parlamentar. Entretanto, um servidor comissionado participou ativamente do projeto desde o início.

\section{O objetivo geral}


O objetivo geral do projeto foi definido como uma contribuição ao aprimoramento teórico/técnico e à articulação entre servidores da Casa, buscando a consolidação de um projeto de parlamento mais orgânico e engajado no processo democrático.

\section{Os objetivos específicos}

Os objetivos específicos foram definidos como:

1. Criar um espaço de estudo e reflexão sobre o "serviço público", seus fundamentos, determinações, e perspectivas no panorama atual da organização sociopolítica e sobre os desafios do Poder Legislativo no processo de consolidação democrática;

2. Oportunizar convivência, intercâmbio de conhecimentos e de experiências entre todos os servidores, contribuindo para superar uma suposta estratificação entre colegas novos e antigos e entre a chamada área administrativa e área política, criando uma unidade plural no corpo funcional.

3. Proporcionar as bases para projetos de pesquisa e de avaliação institucional, a partir das contribuições do próprio corpo funcional da Casa, que possam contribuir para o alcance da missão da Assembléia Legislativa.

\section{O caminho metodológico}

A intenção inicial de nucleação era de dois grupos de 15 servidores da Assembléia Legislativa, voluntários, a partir de critérios inclusivos levando em conta tempo de serviço público, tempo de trabalho na AL, vínculo com o Estado, gênero, idade, formação acadêmica, cargo e função. Cada grupo realizaria 17 encontros, semanais, com duração de duas horas cada um, intercalando discussão, estudo e vivência, em horário de trabalho, durante quatro meses e meio. Na primeira reunião de cada grupo, foi realizada a técnica de Grupo de Discussão. Nas demais, foram realizadas sessões de estudo sobre Democracia, Parlamento e Serviço Público, com leitura prévia de textos indicados e seminários de interpretação e discussão, intercaladas com reuniões de vivência.

\section{O lançamento do projeto e a motivação}

A apresentação pública do projeto foi precedida de ampla divulgação mediante comunicação virtual (página intranet, correio eletrônico individual) a cada servidor da Assembléia Legislativa, bem como por visitas aos setores com entrega individual de carta convite, visando a 
mais eficaz motivação para o conhecimento da proposta. Toda a equipe da Escola do Legislativo foi envolvida nessa etapa de divulgação/motivação.

No evento, o projeto foi apresentado por meio áudio visual, após o qual foi realizado um pequeno debate. Na saída, fichas de inscrição foram preenchidas, dando início ao projeto com um pequeno reconhecimento mais detalhado da população inscrita. $\mathrm{O}$ projeto foi apresentado à administração superior da Assembléia Legislativa, em reunião de diretores, tendo sido aprovado para imediata implementação.

Para marcar a imagem do projeto, facilitar sua divulgação e incentivar a construção de uma identidade para os grupos participantes, foi criada uma marca utilizada como timbre de correspondência, adesivo para pasta de textos, marcador de livros, cartazes e folders. A marca foi muito bem aceita e ajudou muito a fixação da idéia de que "estudar É trabalhar".

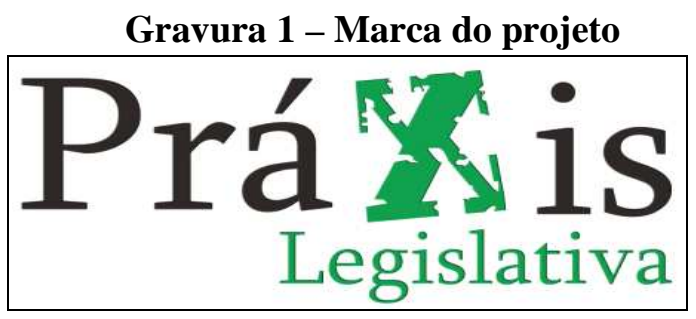

\section{A nucleação e o perfil dos grupos}

Os grupos foram nucleados a partir de indicação de disponibilidade de horários. Todas as demais informações constantes nas fichas de inscrição foram utilizadas para elaboração de perfil de participantes, mapeamento de temas potenciais e subsídios secundários para análise dos dados obtidos em grupo de discussão.

Participaram do projeto Práxis Legislativa 39 servidores e servidoras, distribuídos em três grupos de trabalho. Quanto ao vínculo com o Estado, apenas um participante era Cargo em Comissão. Todos os demais eram servidores públicos efetivos, do quadro da Casa.

- As mulheres representaram o dobro do que os homens, conforme demonstra a tabela abaixo: 
Tabela 1 - Distribuição dos participantes por gênero

\begin{tabular}{|l|l|l|l|}
\hline \hline GRUPO & MULHERES & HOMENS & TOTAL \\
\hline 1 & 4 & 10 & 14 \\
\hline 2 & 4 & 5 & 9 \\
\hline 3 & 5 & 11 & 16 \\
\hline TOTAL & 13 & 26 & 39 \\
\hline
\end{tabular}

- Quase 70\% (31 participantes) era de idades acima de 40 anos.

Tabela 2 - Distribuição dos participantes por idade

\begin{tabular}{||l|l|l|l||}
\hline GRUPO & ATÉ 40 ANOS & ACIMA DE 40 ANOS & TOTAL \\
\hline 1 & 2 & 12 & 14 \\
\hline 2 & 2 & 7 & 9 \\
\hline 3 & 4 & 12 & 16 \\
\hline TOTAL & 8 & 31 & 39 \\
\hline
\end{tabular}

- Quanto ao local de trabalho, a distribuição foi paritária, sendo metade (19) na área administrativa e metade na área legislativa (20).

Tabela 3 - Distribuição dos participantes por local de trabalho

\begin{tabular}{|l|l|l|l||}
\hline GRUPO & ÁREA ADMINISTRATIVA & ÁREA LEGISLATIVA & TOTAL \\
\hline 1 & 7 & 7 & 14 \\
\hline 2 & 5 & 4 & 9 \\
\hline 3 & 7 & 9 & 16 \\
\hline TOTAL & 19 & 20 & 39 \\
\hline
\end{tabular}

- $\quad 70 \%$ dos participantes tinham formação superior completa, sendo 5 com pós-graduação.

Tabela 4 - Distribuição dos participantes por formação acadêmica

\begin{tabular}{|l|l|l|l|l|l||}
\hline GRUPO & SUP. INCOMP. & SUP. COMP. & PÓS GRAD. & EM BRANCO & TOTAL \\
\hline 1 & 1 & 11 & 2 & - & 14 \\
\hline 2 & - & 7 & 1 & 1 & 9 \\
\hline 3 & - & 14 & 2 & - & 16 \\
\hline TOTAL & 1 & 32 & 5 & 1 & 39 \\
\hline
\end{tabular}


- 21 participantes não declararam ter projeto profissional ou acadêmico definido;

- 11 afirmaram ter projeto de ascensão profissional dentro da Assembléia Legislativa;

- 7 pretendiam iniciar o segundo curso superior;

- 8 planejavam fazer pós graduação,

- 3 fariam alguma especialização.

Tabela 5 - Distribuição dos participantes por projeto profissional

\begin{tabular}{|l|l|l|l|l|l||}
\hline GRUPO & EM BRANCO & NA AL & FORA DA AL & OUTROS & TOTAL \\
\hline 1 & 8 & 3 & 1 & 2 & 14 \\
\hline 2 & 2 & 5 & - & 2 & 9 \\
\hline 3 & 11 & 3 & 2 & - & 16 \\
\hline TOTAL & 12 & 11 & 3 & 4 & 39 \\
\hline
\end{tabular}

Tabela 6 - Distribuição dos participantes por projeto acadêmico

\begin{tabular}{|l|l|l|l|l|l||}
\hline GRUPO & EM BRANCO & GRADUAÇÃO & PÓS GRAD. & APERF. & TOTAL \\
\hline 1 & 6 & 5 & 2 & 1 & 14 \\
\hline 2 & 4 & 2 & 2 & 1 & 9 \\
\hline 3 & 11 & - & 4 & 1 & 16 \\
\hline TOTAL & 21 & 7 & 8 & 3 & 39 \\
\hline
\end{tabular}

Quanto ao tempo de serviço público dentro e fora da Assembléia, o perfil médio dos participantes assim se configurou:

- 27 participantes tinham mais de 10 anos de serviço público, sendo desses, 18 com mais de 20 anos de serviço público;

- 7 participantes tinham até 3 anos de serviço público;

- 5 participantes tinham entre 3 e 10 anos.

Tabela 7 - Distribuição dos participantes por tempo de serviço público

\begin{tabular}{|l|l|l|l|l|l||}
\hline GRUPO & ATÉ 3 ANOS & 3 A 10 ANOS & 10 A 20 ANOS & +20 ANOS & TOTAL \\
\hline 1 & 2 & 4 & 2 & 6 & 14 \\
\hline 2 & 2 & - & 3 & 4 & 6 \\
\hline 3 & 3 & 1 & 4 & 8 & 16 \\
\hline TOTAL & 7 & 5 & 9 & 18 & 39 \\
\hline
\end{tabular}

A distribuição do tempo de serviço na Assembléia Legislativa foi igual:

- a metade com mais de 10 anos e a outra metade com menos de 10 anos. 
- 13 participantes tinham até 3 anos de trabalho na Assembléia Legislativa.

Tabela 8 - Distribuição dos participantes por tempo de trabalho na Assembléia Legislativa

\begin{tabular}{|l|l|l|l|l|l||}
\hline GRUPO & ATÉ 3 ANOS & 3 A 10 ANOS & 10 A 20 ANOS & +20 ANOS & TOTAL \\
\hline 1 & 7 & - & 1 & 6 & 14 \\
\hline 2 & 2 & - & 4 & 3 & 9 \\
\hline 3 & 4 & 5 & 3 & 4 & 16 \\
\hline TOTAL & 13 & 5 & 8 & 13 & 39 \\
\hline
\end{tabular}

- 21 participantes trabalhavam na Assembléia Legislativa desde que ingressaram no serviço público.

Tabela 9 - Distribuição dos participantes pela relação entre o tempo de serviço público e de trabalho na Assembléia Legislativa

\begin{tabular}{|l|l|l|l|l||}
\hline \hline GRUPO & IGUAL & ATÉ 3 ANOS & MAIS DE 3 ANOS & TOTAL \\
\hline 1 & 6 & 4 & 4 & 14 \\
\hline 2 & 6 & 3 & - & 9 \\
\hline 3 & 9 & 2 & 5 & 16 \\
\hline TOTAL & 21 & 9 & 9 & 39 \\
\hline
\end{tabular}

Quanto aos cargos e funções, a maioria era taquígrafa. Dos demais, 9 eram diretores ou coordenadores e 9 eram assessores ou técnicos legislativos.

Tabela 10 - Distribuição dos participantes por cargo ou função

\begin{tabular}{||l|l|l|l|l|l|l|l||}
\hline \hline GRUPO & COORD. & DIRET. & ASSES. & TÉCNICO & TAQUÍG. & OUTROS & TOTAL \\
\hline 1 & - & 3 & 3 & 2 & 5 & 1 & 14 \\
\hline 2 & 5 & 2 & 2 & - & - & - & 9 \\
\hline 3 & 2 & - & 2 & - & 6 & 6 & 16 \\
\hline TOTAL & 7 & 5 & 7 & 2 & 11 & 7 & 39 \\
\hline
\end{tabular}

Em resumo, o perfil médio dos participantes do projeto Práxis Legislativa pôde ser assim configurado: mulheres, com mais de 40 anos de idade, das áreas legislativa ou administrativa, com formação superior, sem projeto profissional ou acadêmico declarado, taquígrafas ou detentoras de cargos de chefia, com o dobro de serviço público anterior à Assembléia Legislativa, novas ou antigas na Casa. 


\section{As técnicas}

Tendo em vista que o projeto envolveu as dimensões de pesquisa, estudo e vivência, as técnicas de dinâmica de grupo utilizadas foram: grupos de discussão ou grupos focais; sessões de estudo; sessões de vivência.

\section{Os grupos de discussão}

Grupos de discussão são também denominados grupos focais. O objetivo de aplicação desta técnica foi, principalmente, a produção de fonte primária de informações sobre a experiência cotidiana vivenciada (práxis) pelo conjunto de servidores participantes do projeto, visando ao planejamento das reuniões de vivência e, também, à avaliação final do trabalho de cada grupo e do projeto em geral.

A primeira reunião de vivência de cada grupo foi dedicada à devolução e reflexão sobre resultado obtido nos grupos de discussão. Com isso, cada grupo pode iniciar seu processo de práxis sobre bases construídas pelos próprios membros, o que contribuiu para fundamentar o processo de construção de identidade grupal.

Foram realizados três grupos de discussão, a partir dos ensinamentos de Ibáñez (1992), formados pelos participantes do projeto Práxis Legislativa. Cada grupo produziu um discurso ao mesmo tempo definido e rico, pois contemplaram um tanto de homogeneidade, mas não absoluta.

Foram valorizadas as redes de relações pré-existentes, de modo que cada membro, embora oriundo de uma rede pública (mundo do trabalho), participasse do grupo mais como pessoa do que como funcionário público, visando a facilitação da comunicação interpessoal.

As questões formuladas para provocar o início das discussões giraram em torno dos objetivos do trabalho de cada um na Assembléia Legislativa, como servidores públicos estaduais, os dilemas do cotidiano profissional e a Assembléia Legislativa na estrutura e no contexto político atual.

Uma servidora da equipe da Escola do Legislativo explicou o tema ao grupo e a expectativa com a atividade proposta (FONTANA E FREY, 1998).

O número de membros considerado ideal para um grupo de discussão é entre cinco e dez (IBÁÑEZ 1992), por ser suficientemente representativo de um discurso que, de outra forma, seria difícil investigar. O critério é mais próximo, portanto, de um caráter estratégico do que estatístico de amostragem. A composição contemplou um caráter heterogêneo inclusivo (Idem), pois acolheu diferentes áreas de atuação profissionais que tinham em comum o fato de trabalharem na Assembléia Legislativa do Rio Grande do Sul e o interesse em contribuir para uma atividade de pesquisa sobre sua realidade de trabalho. 
Esses grupos de discussão foram muito ricos, porque trouxeram à tona discursos que desvelaram algumas questões que puderam ser aprofundadas no decorrer do projeto. Com essa técnica, evidenciaram-se, com mais clareza, algumas suposições da equipe a respeito de dualidades relativas ao tempo de serviço público e à natureza do vínculo com o Estado. Trouxeram representações dos técnicos e informações sobre o universo simbólico das redes de relações na instituição.

Surgiram, nesses grupos, os temas da motivação, do compromisso, das relações internas e externas à instituição, dos dilemas do trabalho político e dos vínculos e desencontros entre o trabalho na área administrativa e a parlamentar.

Os três grupos de discussão caracterizaram-se, afinal, por reunir um rico material que, articulado aos dados oriundos das fundamentações teórica e metodológica do projeto, formaram um conjunto de dados bastante próximo do almejado para o planejamento da continuidade do projeto.

O trabalho de análise dos dados produzidos a partir dos grupos de discussão deu-se desde a primeira leitura das transcrições, quando foram efetuadas anotações nas margens dos registros, repetidamente, tentando criar listas de categorias recorrentes, significados dos termos, idéias subjacentes, etc. Este método deu origem a uma tipologia de temas e a uma elaboração de conceitos concretos e unificadores, a partir das categorias identificadas, até a intuição de proposições e generalizações que puderam constituir-se num esquema analítico consistente e coerente com a temática da investigação. A relevância dos temas e indicadores não foi definida através de critério quantitativo, ou seja, não foi baseado no número de aparições no conjunto de dados. ${ }^{1}$

A partir disso, foi montado um modelo de análise do material, seguindo livremente as etapas propostas por Huberman e Milles² e Taylor e Bogdan (1998 p. 159-74).

Identificados os temas gerais, codificaram-se os dados e foi elaborada uma primeira compreensão do tema de estudo, mediando com os contextos em que foram produzidos. Para tanto, o material transcrito foi lido diversas vezes, tentando-se identificar chaves de compreensão do todo e das partes.

Como oportunidade de troca de impressões e controle, o material foi oferecido à discussão em reuniões da equipe da Escola do Legislativo. Daí surgiram questões teóricas e metodológicas

\footnotetext{
1 "En la investigación cualitativa no hay líneas guías que determinan la cantidad de datos necesarios para refrendar una conclusión o interpretación. Esto siempre queda sujeto a juicio. (...) un único incidente es suficiente para desarrollar una categoría conceptual para la teoría fundamentada”. (TAYLOR E BOGDAN, 1998, p. 170)

${ }^{2}$ Hubermann e Milles (1998) identificam três processos dentro do que definem como análise de dados: o primeiro é a redução dos dados produzidos a partir de um sistema conceitual previamente eleito pelo pesquisador, de questões de pesquisa, identificação de casos e utilização de instrumentos. Trata-se, em resumo, de uma seleção e de uma condensação criteriosa dos dados obtidos. O segundo consiste na organização dos dados já reduzidos na etapa antecedente, a fim de possibilitar uma reflexão, através de sumários, sinopses, diagramas, etc. O terceiro processo envolve a atividade analítica estrita, que é a sugestão de significados para os dados organizados. Consistem na busca de padrões, temas, questões, exceções, surpresas, etc.
} 
que também contribuíram para o desenho do modelo de análise e dos procedimentos metodológicos referentes à implementação das reuniões dos grupos.

\section{As sessões de estudo}

A bibliografia oferecida para estudo foi, conforme o projeto inicial, elaborada no sentido de contemplar três eixos de reflexão: sobre o Estado de Direito e Democracia; sobre o Serviço Público; sobre o Poder Legislativo ${ }^{3}$. As reuniões de estudos foram intercaladas com reuniões de vivência, visando a realização do conceito de práxis - pensar fazendo, fazer pensando.

Os temas específicos propostos para estudo foram: Estado de Direito, Democracia; o parlamento na consolidação democrática (na garantia dos direitos fundamentais, na fiscalização da implementação das políticas públicas e na avaliação normativa); o serviço público ("espírito", crise e alternativas teóricas; determinações da organização do serviço público no Brasil; crítica, autocrítica e alternativas).

No início, foi proposta a leitura de cada texto em duas partes, composta de aproximadamente 50 (cinqüenta) páginas (8 capítulos) cada uma, com prazo de 15 dias entre os encontros. Com isso, seria estudada uma obra por mês, realizando uma aproximação inicial sobre Estado de Direito e Democracia em 2 meses de trabalho em grupo.

Esse método apresentou duas dificuldades para os grupos em geral. De um lado, esse ritmo de leituras demonstrou-se de difícil realização - os participantes combinaram reduzir a quantidade de leitura quinzenal para a metade. De outro lado, os conteúdos das obras foram objetos de bastante estranhamento para a maioria dos participantes, causando resistências a "mergulhar" nas lógicas dos autores, no sentido de estudo propriamente dito. Em vez disso, a tendência foi de utilização dos textos como fontes de "inspiração" para debates sobre atualidade político-econômica brasileira e sobre a realidade cotidiana de trabalho - a Assembléia Legislativa. O caráter multidisciplinar dos grupos e a distância do hábito de estudar em grupos são fatores que podem ter contribuído para essa forma de relacionamento com a bibliografia utilizada.

Após a leitura desses dois textos, cada grupo decidiu, em processo de avaliação, dedicar-se a um tema distinto, dentro da proposta inicial do projeto. Assim, o planejamento para o segundo semestre do projeto incluiu as temáticas: Ética, Serviço Público e Política.

\footnotetext{
${ }^{3}$ Exemplos de bibliografia sugerida pela coordenação do projeto e utilizada pelos grupos: Bobbio: Liberalismo e Democracia; Bresser Pereira: Exposição de motivos interministerial no 49; Canotilho: Estado de Direito; Coelho: Sobre o artigo "A crise do espírito de serviço público"; Maquiavel: O príncipe; Parada: Sistemas de função pública; Ramió Matas: Os problemas da implementação da nova gestão pública nas administrações públicas latinas: modelo de Estado e cultura institucional; Santos: Reforma administrativa no contexto da democracia - experiências e modelos internacionais para organização da função pública; Supiot: A crise do espírito de serviço público; Weber: ciência e política; Filmes: o ponto de mutação; senhor das armas; o jardineiro fiel.
} 
O primeiro grupo, dedicado à Ética, decidiu estudar a partir de contribuições diversas sobre o tema, levados em cada reunião pelos participantes. Decidiu, também, tentar produzir algum texto a partir das leituras e discussões, visando publicação. O segundo grupo, dedicado ao tema Serviço Público, decidiu "mergulhar" no assunto mediante estudo de autores sugeridos pela equipe da Escola do Legislativo. A partir daí, também planejou elaborar uma síntese comentada, relacionando o estudo a alguma questão própria da realidade vivenciada na Assembléia Legislativa. O terceiro grupo, que havia planejado estudar o tema Política, não voltou a reunir-se no segundo semestre, tendo sido realizada tentativa de renucleação no ano seguinte.

\section{As sessões de vivência}

As reuniões de vivência foram concebidas para serem dedicadas a debates sobre temas trazidos pelo próprio grupo, a partir da experiência cotidiana de trabalho e/ou suscitados pelos estudos realizados. Foram realizadas de forma mais ou menos articulada ao estudo teórico. O processo indicou que a separação rígida entre reuniões de estudo e reuniões de vivência foi difícil de manter, pois a tendência mais forte era a de intercalarem-se leituras e debates na mesma reunião. Isso demonstrou um potencial importante de criatividade, articulação e propositividade entre os participantes, mas dificultou um pouco o alcance de um dos objetivos do projeto, que era o aprofundamento teórico.

As hipóteses iniciais do projeto e os temas inferidos das informações colhidas durante os grupos de discussão foram, de forma geral, coincidentes com os conteúdos das sessões de vivência. Tempo de serviço, conteúdo do trabalho, imagem/auto-imagem da Assembléia Legislativa, da política em geral foram assuntos trazidos à tona nos três grupos.

A vivência esteve presente, portanto, de forma constante, durante todas as reuniões dos grupos, seja de discussão, seja de estudo. Assim, confirmou-se uma suposta demanda reprimida de escuta mútua por parte dos servidores, que encontrou canal apropriado no projeto Práxis Legislativa.

A dinâmica adotada nos três grupos foi a de escuta sobre o cotidiano de trabalho de cada participante, por meio de relatos e debates sobre as peculiaridades de cada setor (atividades, dificuldades, potencialidades). Após essa escuta sobre a vivência de cada um, os temas tratados passaram a ser, pouco a pouco, mais articulados às leituras teóricas.

\section{A avaliação}

A avaliação do projeto foi realizada a partir dos critérios do interesse temático (demanda de voluntários para os grupos, freqüência e continuidade), viabilidade prática (liberação das chefias 
imediatas, freqüência, horários), metodologia (dinâmica dos grupos, didática dos seminários, facilitação das vivências, assessoria do grupo de discussão), conteúdo dos grupos de estudo (pertinência dos temas, qualidade da bibliografia, debates) e conteúdo das reuniões de vivência (temas trazidos, participação nos debates, diagnóstico e propostas emergentes). A avaliação periódica individual e grupal também constituíram elementos de avaliação do projeto.

A avaliação referente ao primeiro semestre de implementação do projeto indicou que houve interesse inicial pelos temas sugeridos para estudo, mas, pouco a pouco, cada grupo foi revelando uma peculiaridade no manejo com a bibliografia. Enquanto dois grupos mantiveram um ritmo quinzenal de estudo, um grupo não desenvolveu o hábito de leitura e estudo, preferindo sempre realizar debates mais próximos ao conteúdo das reuniões de vivência.

Quanto à viabilidade prática de participação, a freqüência nas reuniões oscilou bastante, permanecendo, em cada grupo, um pequeno número de participantes assíduos em todas as reuniões. As ausências e atrasos eram sempre justificados como devidos a compromissos de trabalho.

O processo de avaliação coletiva ocorreu no final de cada semestre de implementação do projeto, mediante debates a partir das seguintes questões:

1. Avaliação do projeto: idéia original, temática proposta, método, coordenação, alcance dos objetivos;

2. Avaliação do grupo: características mais marcantes, atividades de estudo, de vivência, novidades.

3. Propostas para os grupos e para o projeto;

Os resultados desse processo de avaliação podem ser resumidos como segue:

O projeto foi visto pelos participantes como oportunidade de resgate de um espaço privilegiado para o estudo e a reflexão. O projeto alcançou seus objetivos, justificando o esforço de todos num movimento criativo e produtivo. O enfoque foi considerado desafiador. Sentiu-se a falta de espaço permanente para as reuniões. Foi sugerido divulgar-se mais o projeto para ampliá-lo, a realização de visitas mensais aos setores dos colegas participantes do práxis, encontros periódicos entre todos os grupos com palestrantes, abertas aos demais colegas da Casa, como atividades do Projeto Práxis Legislativa.

Foi sublinhado o caráter democrático do manejo da coordenação nas reuniões, mas também a possibilidade de maior intervenção em ações de incentivo à participação. A coordenação manteve o espírito do projeto, mas foi sugerida a possibilidade de maior ingerência nas reuniões de estudos; faltou também metodologia de convivência; a condução dos grupos foi considerada, também, excessivamente aberta. Foi sugerida a montagem de um formulário mais completo para orientar a coordenação. Quanto à metodologia de estudo, foi sugerido que a coordenação motivasse e esclarecesse o objetivo de cada texto. 
Reconheceu-se, por outro lado, a autonomia desenvolvida, que possibilitou a criação de identidade dos grupos. A heterogeneidade do perfil dos participantes facilitou as discussões teóricas. Mas a redução do número de participantes no decorrer do período foi atribuída, além de dificuldades de conciliar a atividade em horário de trabalho, ao enfoque excessivamente jurídico dos textos. Um grupo rejeitou inteiramente os textos propostos. Faltou, também, o registro da memória dos grupos. Foi sugerido o estímulo à criação de mais um grupo, além de agregar pessoas aos grupos já formados, mas cuidando o tamanho dos grupos (máximo de 15 participantes). O grupo novo poderia ter características mais suaves, leituras durante a própria reunião, reforçando a vivência. Também foi sugerida a realização de atividades para integrar os grupos, como mais encontros de avaliação e planejamento. Foi decidida a realização das reuniões mesmo sem a presença da coordenação e a manutenção dos horários combinados pelos grupos.

Cada grupo foi adquirindo uma cara própria, na medida do tempo de convivência e da experiência de leituras e discussões. Identificaram, assim, suas temáticas preferidas e seu ritmo ideal de leituras e debates. Assim, cada grupo optou por construir sua própria metodologia de estudos para o período seguinte. Um deliberou estudar o tema Ética a partir de textos leves, curtos, propostos e preparados pelos próprios participantes do grupo. Outro decidiu estudar Política a partir de textos considerados clássicos, apresentados cada vez por um participante. O terceiro grupo resolveu centrar mais suas atividades no estudo sobre o tema Serviço Público, também responsabilizando cada vez um membro pela apresentação do texto.

Quanto ao conteúdo, o estudo foi pouco aprofundado, pois os textos foram considerados complexos, para tão pouco tempo para a leitura. As temáticas foram bem recebidas, mas mal aproveitadas, com pouco estudo teórico, sendo os textos utilizados como inspiração para discussões políticas e sobre o cotidiano do trabalho na Assembléia Legislativa. A quantidade de textos foi considerada excessiva para a realidade dos participantes. Foi sugerido manter-se a complexidade, mas com textos mais curtos, viabilizando estudo com maior consistência, mediante a criação de uma metodologia de estudo em grupo. Cada texto deveria ser relatado por um participante, responsável por conduzir a discussão. Também foi levantada a possibilidade de enriquecimento dos debates a partir de filmes, entrevistas, etc. Foi planejado, finalmente, que cada grupo tentasse produzir artigos sobre os temas estudados para publicação.

\section{Considerações finais}

"Práxis Legislativa - pensar fazendo, fazer pensando" foi uma experiência inovadora, no sentido de extrapolar os limites do formato de cursos ou seminários para formação continuada. Mas um limite não pôde ser superado: o da transitoriedade da gestão pública no parlamento, que faz com 
que projetos como este sejam, muitas vezes, descontinuados em função de rearranjos políticos incidindo sobre a administração da Assembléia Legislativa. Mesmo assim, o projeto foi um marco na trajetória de construção de um corpo funcional qualificado e unido na Assembléia Legislativa do Rio Grande do Sul. Apoiado formalmente pela administração e com boa receptividade por parte dos colegas, o projeto representou, também, uma das marcas da gestão da Escola do Legislativo naquele biênio, considerada como referência para o conjunto de instituições afins no Brasil.

\section{Referências bibliográficas}

BOBBIO, Norberto. Liberalismo e Democracia. São Paulo:Brasiliense, 2005.

CANOTILHO, José Joaquim Gomes. Estado de Direito. Lisboa: Gradiva; Fundação Mario Soares. Cadernos Democráticos, s.d.

FONTANA, Andréa e FREY, James H. Interviewing: the art of science. In: DENZIN, Norma K. e LINCOLN, Yvonna (edits). Collecting and interpreting qualitative materials. Londres: Sage, 1998. COELHO, Rogério Viola. Sobre o artigo "A crise do espírito de serviço público". Adverso.

Revista da Associação de Docentes da Ufrgs, ano V, n. 7, julho de 1995. p. 13-15.

IBÁÑEZ, Jesús. Más allá de la sociologia - el grupo de discusión: técnica y crítica. 3. ed. Madrid: Siglo Veinteuno, 1992.

HUBERMANN, A. MICHELS E MILLES, Matthew. Data management and analisiys methods. In: DENZIN, Norma K. e LINCOLN, Yvonna (edits). Collecting and interpreting qualitative materials. Londres: Sage, 1998.

MAQUIAVEL, Nicolau. O príncipe. São Paulo: Martins Fontes, 2001.

PARADA, Ramón. Sistemas de função pública. In: . Derecho administrativo II. Organización y empleo público. 7. ed. Madrid: Marcial Pons Ediciones Jurídicas, 1993, p. 373-400.

PEREIRA, Bresser: Exposição de motivos interministerial n ${ }^{\circ} 49$. digit.

RAMIÓ MATAS, Carles. Los problemas de la implantación de la nueva gestión pública em lãs administraciones públicas latinas: modelo de Estado y cultura institucional. Revista del CLAD Reforma y Democracia, n. 21, octubre 2001, p. 77-115

SUPIOT, Alan. A crise do espírito de serviço público. Adverso. Revista da Associação de Docentes da Ufrgs, ano V, n. 7, julho de 1995, p. 16-25.

TAYLOR, S.J. e BOGDAN, R. Introducción a los métodos cualitativos de investigación. Barcelona: Piados Básica, 1998.

WEBER, Max. Ciência e Política - duas vocações. São Paulo: Cultrix, 2004. 